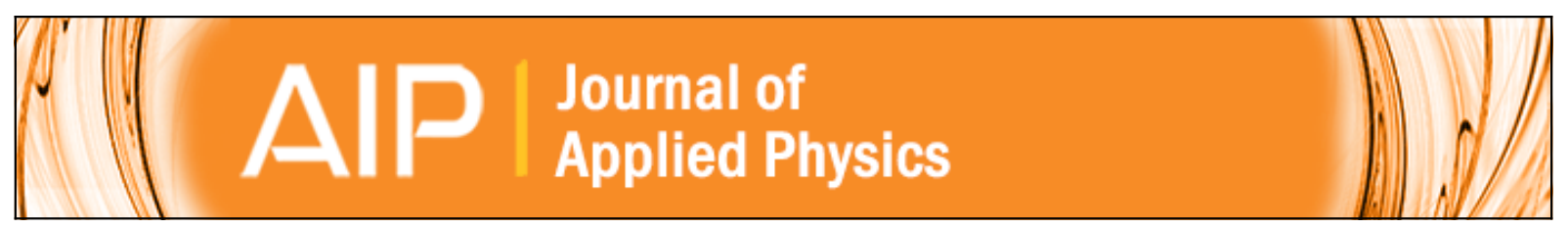

\title{
Low magnetisation alloys for in-plane spin transfer torque devices
}

K. Oguz, M. Ozdemir, O. Dur, and J. M. D. Coey

Citation: Journal of Applied Physics 111, 113904 (2012); doi: 10.1063/1.4723824

View online: http://dx.doi.org/10.1063/1.4723824

View Table of Contents: http://scitation.aip.org/content/aip/journal/jap/111/11?ver=pdfcov

Published by the AIP Publishing

\section{Articles you may be interested in}

Spin torque ferromagnetic resonance with magnetic field modulation

Appl. Phys. Lett. 103, 172406 (2013); 10.1063/1.4826927

Magnetization dynamics of a MgO-based spin-torque oscillator with a perpendicular polarizer layer and a planar free layer

J. Appl. Phys. 112, 083907 (2012); 10.1063/1.4758308

Spin-torque diode spectrum of ferromagnetically coupled $(\mathrm{FeB} / \mathrm{CoFe}) / \mathrm{Ru} /(\mathrm{CoFe} / \mathrm{FeB})$ synthetic free layer J. Appl. Phys. 111, 07 C917 (2012); 10.1063/1.3679416

Magnetic tunnel junctions with Co-based perpendicular magnetic anisotropy multilayers

J. Vac. Sci. Technol. A 28, 973 (2010); 10.1116/1.3430549

Correlation of telegraph noise between parallel and antiparallel states of magnetic tunnel junctions

J. Appl. Phys. 97, 10C911 (2005); 10.1063/1.1851952

\section{High-Voltage Amplifiers}

-Voltage Range from $\pm 50 \mathrm{~V}$ to $\pm 60 \mathrm{kV}$

- Current to $25 \mathrm{~A}$

\section{Electrostatic Voltmeters}

- Contacting \& Non-contacting

- Sensitive to $1 \mathrm{mV}$

- Measure to $20 \mathrm{kV}$
ENABLING RESEARCH AND

INNOVATION IN DIELECTRICS,

ELECTROSTATICS, MATERIALS, PLASMAS AND PIEZOS

Rek www.trekinc.com 


\title{
Low magnetisation alloys for in-plane spin transfer torque devices
}

\author{
K. Oguz, ${ }^{1}$ M. Ozdemir, ${ }^{2}$ O. Dur, ${ }^{3}$ and J. M. D. Coey ${ }^{1}$ \\ ${ }^{1}$ School of Physics and CRANN, Trinity College, Dublin 2, Ireland \\ ${ }^{2}$ Department of Physics, Faculty of Science, Marmara University, Istanbul, Turkey \\ ${ }^{3}$ Calik Holding, Energy, Information and Communication Group, Zincirlikuyu, Istanbul, Turkey
}

(Received 11 January 2012; accepted 1 May 2012; published online 1 June 2012)

\begin{abstract}
Magnetic properties of thin films of three in-plane alloy systems, namely, $\mathrm{Co}_{40} \mathrm{Ni}_{40-\mathrm{x}} \mathrm{Cr}_{\mathrm{x}} \mathrm{B}_{20}$, $\mathrm{Co}_{40} \mathrm{Fe}_{40-x} \mathrm{Ni}_{\mathrm{x}} \mathrm{B}_{20}$, and $\mathrm{Co}_{40} \mathrm{Fe}_{40-\mathrm{x}} \mathrm{Cr}_{\mathrm{x}} \mathrm{B}_{20}$ are investigated with a view to reducing the critical current density $\left(j_{c}\right)$ for spin transfer torque switching in $\mathrm{MgO}$ barrier magnetic tunnel junction nanopillars. In all three systems, the saturation magnetisation, $M_{s}$, decreases with increasing $\mathrm{Cr}$ or Ni substitution. The $\mathrm{Co}_{40} \mathrm{Fe}_{40-\mathrm{x}} \mathrm{Cr}_{\mathrm{x}} \mathrm{B}_{20}$ alloy system is found to be the best in terms of reducing $M_{s}$, while maintaining a high tunnel magnetoresistance ratio. Ferromagnetic resonance experiments revealed that the damping coefficient of $\mathrm{CoFeCrB}$ alloy remains unchanged with increasing $\mathrm{Cr}$ content, but $j_{c}$ is reduced by a factor of four to $4.9 \times 10^{5} \mathrm{~A} / \mathrm{cm}^{2}$ by using a $\mathrm{Co}_{40} \mathrm{Fe}_{32.7} \mathrm{Cr}_{7.3} \mathrm{~B}_{20}$ free layer while maintaining a magnetoresistance of around $60 \%$. (C) 2012 American Institute of Physics. [http://dx.doi.org/10.1063/1.4723824]
\end{abstract}

\section{INTRODUCTION}

Following the prediction of spin transfer torque (STT) associated with spin polarized current in magnetic multilayers by Slonczewski and Berger in 1996, ${ }^{1,2}$ there has been great interest in the spin torque related effects in both giant magnetoresistive (GMR) spin valves and magnetic tunnel junctions (MTJ) due to their potential application as memory elements and microwave oscillators. ${ }^{3-7}$ STT can cause precession or complete magnetic reversal of the free layer magnetisation, depending on the magnitude of the spin-polarized current. $^{1,8,9}$ The critical current density $\left(j_{c}\right)$ for magnetisation switching for in-plane devices depends mainly on the square of the saturation magnetisation $\left(M_{\mathrm{s}}\right)$ of the free layer, due to the demagnetizing field in the layer. ${ }^{9}$ Zero temperature macro-spin calculation ${ }^{9}$ reveals a stability threshold current density of

$$
J_{c}^{A P-P}=\frac{2 e}{\hbar} \frac{\alpha \mu_{0} M_{s} t}{\eta(\pi)}\left(H+H_{d i p}+H_{k}+M_{s} / 2\right) .
$$

Here $\alpha$ is the Landau-Lifshitz-Gilbert (LLG) damping coefficient and $t$ is the thickness of the free layer. The spin transfer efficiency, $\eta$, is a function of the current polarity, polarization, and the relative angle between the free and pinned layers. $H$ is the external field, $H_{d i p}$ is the dipolar coupling between the free and the pinned layers, and $H_{k}$ is the uniaxial anisotropy field. For in-plane devices, the $M_{\mathrm{S}} / 2$ term is much larger than the other terms in the expression. Hence, the critical current density is dominated by the saturation magnetisation of the free layer. Typically, $j_{c}$ has been found to be around $3 \times 10^{6} \mathrm{~A} / \mathrm{cm}^{2}$ for magnesium oxide $(\mathrm{MgO})$ based MTJs. $^{7}$ It is desirable to reduce it to $\sim 5 \times 10^{5} \mathrm{~A} / \mathrm{cm}^{2}$ for memory applications. ${ }^{10}$

There are three approaches to achieve this: the magnetisation or the Gilbert damping of the ferromagnet should be reduced or the spin transfer efficiency should be improved. Here, we investigate the effect of reducing the magnetisa- tion. Amorphous ferromagnetic alloys are good candidates because $M_{\mathrm{s}}$ can easily be controlled by adjusting the transition metal composition or the amount of metalloid in the alloy. ${ }^{11}$ Amorphous Co-Fe-B re-crystallized on a (001) oriented $\mathrm{MgO}$ barrier is proven to be the best way to obtain a high performance MTJ. ${ }^{7,12-16} \mathrm{~A} \mathrm{Co}_{40} \mathrm{Fe}_{40} \mathrm{~B}_{20}$ composition is often used, which has a magnetization of $\sim 1200 \mathrm{kA} / \mathrm{m}$. It is possible to reduce $M_{\mathrm{s}}$ by substituting iron/cobalt with chromium or nickel. In this study, we prepared and characterized magnetisation and Gilbert damping of three series of thin films with compositions $\mathrm{Co}_{40} \mathrm{Ni}_{40-\mathrm{x}} \mathrm{Cr}_{\mathrm{x}} \mathrm{B}_{20}, \mathrm{Co}_{40} \mathrm{Fe}_{40-\mathrm{x}}$ $\mathrm{Ni}_{\mathrm{x}} \mathrm{B}_{20}$, and $\mathrm{Co}_{40} \mathrm{Fe}_{40-\mathrm{x}} \mathrm{Cr}_{\mathrm{x}} \mathrm{B}_{20}$. Then, we focused on the latter system and investigated the magnetoresistance and switching current density of $\mathrm{MgO}$ based MTJ nanopillars with a $\mathrm{Co}_{40} \mathrm{Fe}_{40-\mathrm{x}} \mathrm{Cr}_{\mathrm{x}} \mathrm{B}_{20}$ free layer.

\section{EXPERIMENTAL METHODS}

Thin film stacks and devices in this study were prepared in our Shamrock sputtering system with a base pressure below $2.0 \times 10^{-8}$ Torr. Thin films of the amorphous alloys were deposited by co-sputtering from a combination of two of the high purity (99.95\%) $\mathrm{Co}_{40} \mathrm{Fe}_{40} \mathrm{~B}_{20}, \mathrm{Co}_{40} \mathrm{Cr}_{40} \mathrm{~B}_{20}$, and $\mathrm{Co}_{40} \mathrm{Ni}_{40} \mathrm{~B}_{20}$ targets at room temperature (RT) on $\mathrm{Si}(001) /$ $\mathrm{SiO}_{2}(500 \mathrm{~nm})$ substrates. Film thicknesses were nominally $50 \mathrm{~nm}$. Co-Ni-B and $\mathrm{Co}-\mathrm{Cr}-\mathrm{B}$ targets were used for $\mathrm{Co}_{40}$ $\mathrm{Ni}_{40-\mathrm{x}} \mathrm{Cr}_{\mathrm{x}} \mathrm{B}_{20}$ films, similarly $\mathrm{Co}-\mathrm{Fe}-\mathrm{B}$ and $\mathrm{Co}-\mathrm{Ni}-\mathrm{B}$ were used for $\mathrm{Co}_{40} \mathrm{Fe}_{40-} \mathrm{Ni}_{\mathrm{x}} \mathrm{B}_{20}$ films, and $\mathrm{Co}-\mathrm{Fe}-\mathrm{B}$ and $\mathrm{Co}-\mathrm{Cr}-\mathrm{B}$ targets were used for $\mathrm{Co}_{40} \mathrm{Fe}_{40-x} \mathrm{Cr}_{\mathrm{x}} \mathrm{B}_{20}$ films. The composition of the films was adjusted by carefully controlling the deposition rates of each target. High purity (99.9999\%) Argon was used as process gas and the deposition pressure was kept at $6 \times 10^{-3}$ Torr. Thin films were subsequently annealed at 325 or $350^{\circ} \mathrm{C}$ in high vacuum under an in-plane magnetic field of $0.8 \mathrm{~T}$. High quality $\mathrm{MgO}$-based MTJs using a $\mathrm{Co}-\mathrm{Fe}-\mathrm{Cr}-\mathrm{B}$ free layer with a $\mathrm{Si}(001) / \mathrm{SiO}_{2}(500) / \mathrm{Ta}(5) /$ $\mathrm{Ru}(30) / \mathrm{Ta}(5) / \mathrm{Ni}_{81} \mathrm{Fe}_{19}(5) / \mathrm{Ir}_{22} \mathrm{Mn}_{78}(10) / \mathrm{Co}_{90} \mathrm{Fe}_{10}(2.5) / \mathrm{Ru}$ (0.9) $/ \mathrm{Co}_{40} \mathrm{Fe}_{40} \mathrm{~B}_{20}$ (3)/MgO (1.2)/ $\mathrm{Co}_{40} \mathrm{Fe}_{40-\mathrm{x}} \mathrm{Cr}_{\mathrm{x}} \mathrm{B}_{20}$ (2.5)/Ta 
(5)/Ru (5) stacking structure were also fabricated. The numbers in parenthesis represent the layer thickness in nm. MTJs were patterned into $90 \times 170 \mathrm{~nm}^{2}$ rectangular nanopillars using a combination of electron beam lithography and $\mathrm{Ar}^{+}$ ion milling techniques. ${ }^{17}$

The films were examined by $\mathrm{x}$-ray diffraction using $\mathrm{CuK}_{\alpha}$ radiation both as-deposited and after annealing. The only features seen in the diffraction pattern are due to the substrate. The films are amorphous in both states. Film composition was determined using the energy dispersive $\mathrm{x}$-ray (EDX) technique with $15 \mathrm{keV}$ electrons. Magnetic properties of the as-grown and annealed samples were measured using a quantum design superconducting quantum interference device (SQUID) magnetometer (MPMS XL-5) at both room temperature and $4.2 \mathrm{~K}$. Ferromagnetic resonance (FMR) measurements were carried out by using a Bruker EMX model x-band electron spin resonance spectrometer at a microwave frequency of $9.5 \mathrm{GHz}$, at room temperature. The damping coefficients of the films were determined from the ferromagnetic resonance linewidth. Magneto-transport properties of MTJs were determined using a conventional 4-point method.

\section{RESULTS}

\section{A. Magnetisation}

Figure 1(a) illustrates the RT magnetisation curves of $\mathrm{Co}_{40} \mathrm{Ni}_{40-x} \mathrm{Cr}_{\mathrm{x}} \mathrm{B}_{20}$ films grown on $\mathrm{SiO}_{2}$ with different $\mathrm{Cr}$ concentrations for the as-grown samples. For $\mathrm{x}=0$, saturation magnetisation is around $400 \mathrm{kA} / \mathrm{m}$ but it falls dramatically to $3 \mathrm{kA} / \mathrm{m}$ for $\mathrm{x}=13.2$, and the films become paramagnetic at higher concentrations. A single step in the magnetization curve around zero field suggests that a single magnetic phase present in all samples. The reduction of the room temperature magnetisation reflects both the effect of $\mathrm{Cr}$ on the low temperature saturation magnetisation and its effect on the Curie temperature.

The magnetisation curves of $\mathrm{Co}_{40} \mathrm{Fe}_{40-x} \mathrm{Ni}_{\mathrm{x}} \mathrm{B}_{20}$ films grown on $\mathrm{SiO}_{2}$ are shown in Fig. 1(b) for the as-grown samples measured at RT for different Ni concentrations. It seems that $\mathrm{Ni}$ substitution is not very effective at reducing the magnetisation of the film. For $\mathrm{x}=0$, the magnetisation is $984 \mathrm{kA} / \mathrm{m}$, and it falls only to $882 \mathrm{kA} / \mathrm{m}$ when $\mathrm{x}=21.6$. This is a puzzling result because $\mathrm{Ni}$ has a much lower moment $\left(0.6 \mu_{\mathrm{B}}\right)$ compared to $\mathrm{Fe}\left(2.2 \mu_{\mathrm{B}}\right)$.

$\mathrm{Co}_{40} \mathrm{Fe}_{40-\mathrm{x}} \mathrm{Cr}_{\mathrm{x}} \mathrm{B}_{20}$ is the best alloy system from the point of view of controlled and effective reduction in magnetisation. Magnetisation curves of different $\mathrm{Cr}$ concentrations are shown in Fig. 1(c). The magnetisation of the films decreases as the $\mathrm{Cr}$ concentration increases, with a single step close to zero field, indicating that there is only one magnetic phase present in the samples. The saturation magnetisation is $984 \mathrm{kA} / \mathrm{m}$ for $\mathrm{x}=0$, and it decreases to $859 \mathrm{kA} / \mathrm{m}$ for $\mathrm{x}=4.8$ and $235 \mathrm{kA} / \mathrm{m}$ for $\mathrm{x}=18$. A similar behaviour was reported by Kubota et al. ${ }^{18}$ in $\left(\mathrm{Co}_{75} \mathrm{Fe}_{25}\right)_{80-\mathrm{x}} \mathrm{Cr}_{\mathrm{x}} \mathrm{B}_{20}$ films. In their work, magnetisation falls almost to zero for $\mathrm{x}=20$ at $\mathrm{RT}$ because they reduced both $\mathrm{Co}$ and $\mathrm{Fe}$ in the alloy. Therefore, it is expected to have a faster decay of magnetisation.

Besides the room temperature measurements, we have also measured the magnetisation at $4.2 \mathrm{~K}$, and we have
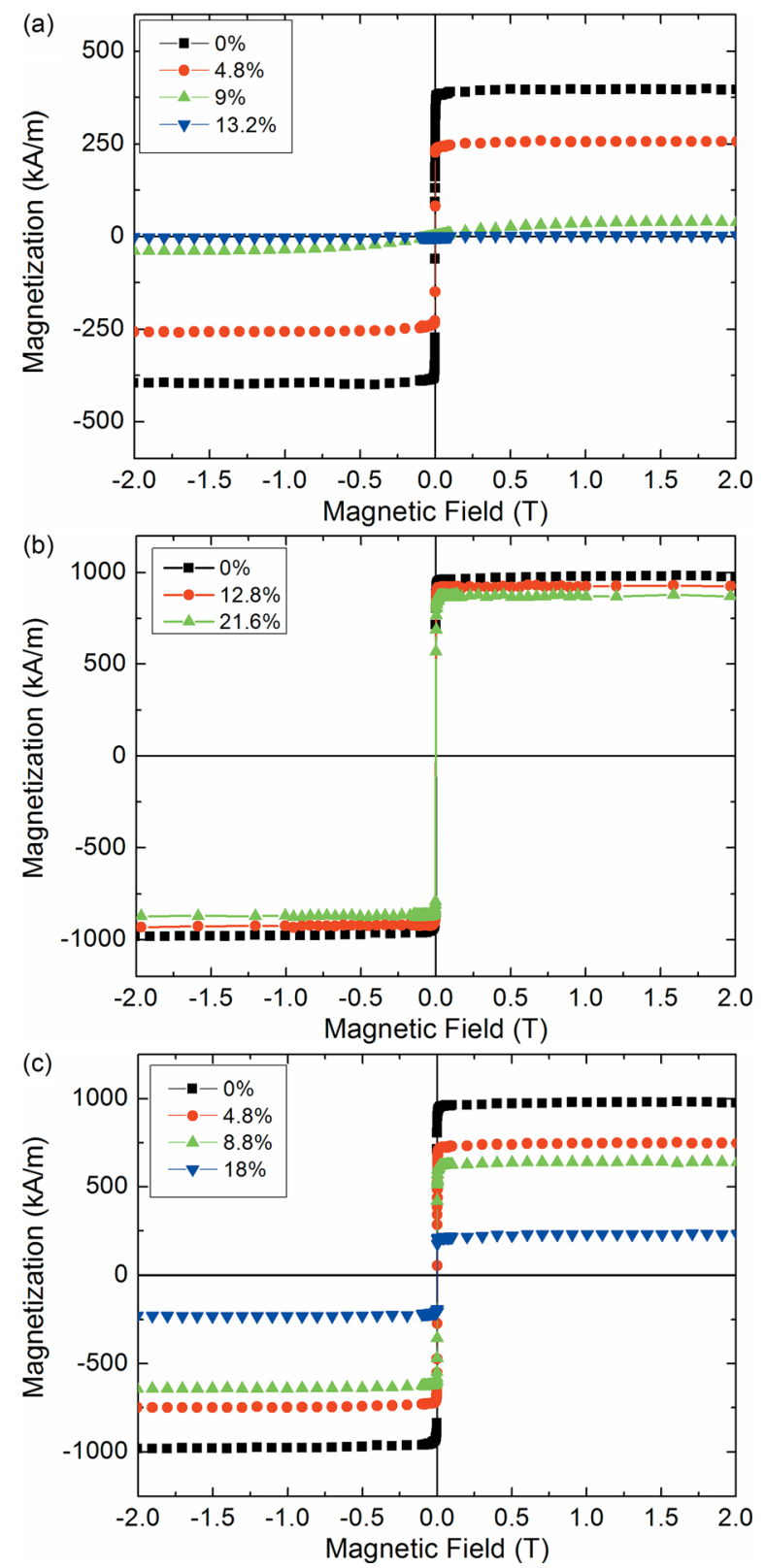

FIG. 1. Magnetisation curves of (a) $\mathrm{Co}_{40} \mathrm{Ni}_{40-\mathrm{x}} \mathrm{Cr}_{\mathrm{x}} \mathrm{B}_{20}$, (b) $\mathrm{Co}_{40} \mathrm{Fe}_{40-\mathrm{x}}$ $\mathrm{Ni}_{\mathrm{x}} \mathrm{B}_{20}$, (c) $\mathrm{Co}_{40} \mathrm{Fe}_{40-\mathrm{x}} \mathrm{Cr}_{\mathrm{x}} \mathrm{B}_{20}$ films on $\mathrm{SiO}_{2}$. Samples were in the as-grown state and measurements were performed at room temperature.

measured it at RT and $4.2 \mathrm{~K}$ after field annealing at $350{ }^{\circ} \mathrm{C}$ in vacuum. The effect of the annealing, which does not crystallize the films, is just to increase the magnetisation slightly, by about $10 \%$. For example, the magnetisation of $\mathrm{Co}_{40} \mathrm{Fe}_{40} \mathrm{~B}_{20}$ increases from 984 to $1110 \mathrm{kA} / \mathrm{m}$ at room temperature and from 1035 to $1150 \mathrm{kA} / \mathrm{m}$ at $4.2 \mathrm{~K}$.

Figure 2 plots the $4.2 \mathrm{~K}$ moments of the as-grown films for the three series. The moment in $\mu_{\mathrm{B}} /$ formula is derived from the measured film moment, $\mu=M \mathrm{~V}$ in $\mathrm{Am}^{2}$, where $\mathrm{V}$ is the film volume using

$$
\mu=M M_{W} / 1000 \rho N_{0} \mu_{B},
$$

where $M_{w}$ is the molecular weight of the formula, $N_{0}$ is Avogadro's number, and density $\rho\left(\mathrm{kg} / \mathrm{m}^{3}\right)$ is estimated by assuming random dense packing with a packing fraction of 


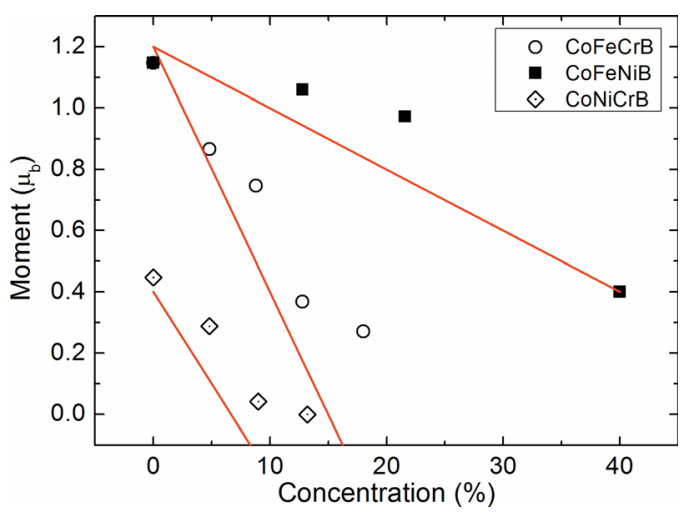

FIG. 2. Magnetic moment per formula measured at $4.2 \mathrm{~K}$ versus concentration of $\mathrm{Cr} / \mathrm{Ni}$ in three alloy systems. Red lines are fits from the magnetic valence model.

0.64 for the transition metal atom. The boron is supposed to occupy voids in the Bernal structure.

\section{B. Ferromagnetic resonance}

The FMR spectra were recorded as a function of $\mathrm{dc}$ magnetic field applied for different directions with respect to the film normal. In the FMR experiment, the ac (microwave) magnetic field component remains always perpendicular to the dc field in order to record the ac magnetic susceptibility, the imaginary component of which is proportional to the microwave absorption (FMR signal). The microwave frequency was kept fixed at about $9.5 \mathrm{GHz}$, while the dc field was scanned through the resonance. The spectra were recorded for all three series. The data for $\mathrm{Co}_{40} \mathrm{Fe}_{40-\mathrm{x}} \mathrm{Cr}_{\mathrm{x}} \mathrm{B}_{20}$ in the parallel and perpendicular directions are shown in Fig. 3. The spectra for $\mathrm{Co}_{40} \mathrm{Fe}_{40-\mathrm{x}} \mathrm{Ni}_{\mathrm{x}} \mathrm{B}_{20}$ are similar but the linewidths for $\mathrm{Co}_{40} \mathrm{Ni}_{40-\mathrm{x}} \mathrm{Cr}_{\mathrm{x}} \mathrm{B}_{20}$ are about four times greater.

We have developed a computer program to deduce the magnetic parameters of the material from fits of the experimental FMR spectra using the model discussed previously. ${ }^{19}$
The damping parameter has a major influence on the resonance line shape. Magnetic damping is usually characterized by the phenomenological damping parameter $\alpha$, which can have both intrinsic and extrinsic contributions. The latter includes surface effects, which may be particularly important in patterned magnetic nanostructures. ${ }^{20}$ We get satisfactory fits between the experimental and the simulated line shapes of the field derivative FMR spectra for a general direction of external dc field with Gilbert type damping for magnetically homogeneous films. The experimental FMR spectra were fitted using Zeeman, demagnetizing and other anisotropy energies along the film plane and in the perpendicular direction in the same calculation.

The measured spectra (black) and calculated spectra (red) are plotted together in Fig. 3. As seen from this figure, the agreement between experimental and fitted values is satisfactory. In some cases, two exchange coupled components were used in the fits. The FMR spectra strictly depend on the composition of the films. The resonance field, the line-width, and even number of the resonance peaks change with the chemical composition. The differences of the resonance fields for parallel and perpendicular geometries can be taken as a rough measure of the dc magnetisation. This means that chromium tends to decrease the magnetisation as we already know from the magnetisation measurements (Fig. 1). The single FMR peak that is observed for samples with low or zero chromium concentration is doubled for the possibly inhomogeneous samples with higher chromium content ( $x=18$ in Fig. 3). The double peaks can be taken as an indication of compositional inhomogenity across the thickness of the sample. The linewidth and amplitudes of the spectra for parallel and perpendicular geometries are found to be slightly different. This difference implies the presence of extrinsic damping effects in addition to the intrinsic Gilbert type damping. Damping is much larger in $\mathrm{Cr}-\mathrm{Ni}$ series $(\alpha \sim 0.03-0.07)$ than in the Co-Fe series $(\alpha \sim 0.01-0.02)$. Structural inhomogenity, especially at the surface, can
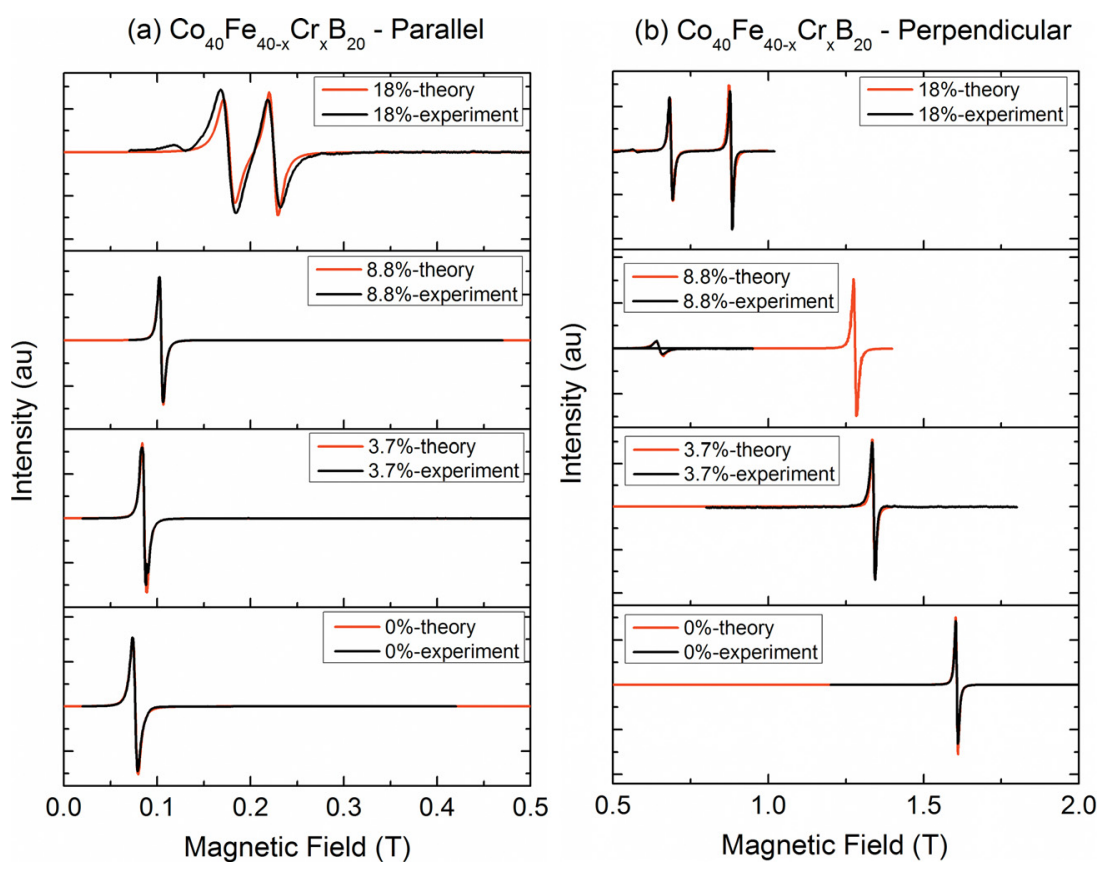

FIG. 3. Ferromagnetic resonance spectra of annealed $\mathrm{Co}_{40} \mathrm{Fe}_{40-\mathrm{x}} \mathrm{Cr}_{\mathrm{x}} \mathrm{B}_{20}$ films. DC magnetic field is applied (a) parallel and (b) perpendicular to the film plane. 
TABLE I. FMR data obtained at room temperature on annealed films with different compositions. The data is given for the measurements in parallel direction.

\begin{tabular}{llcrcc}
\hline \hline & & \multicolumn{1}{c}{$M_{s}$} & \multicolumn{1}{c}{$M_{s}$} & & \\
Sample & & $\begin{array}{c}\text { (SQUID) } \\
(\mathrm{FA} / \mathrm{m})\end{array}$ & $\begin{array}{c}\mu_{0} H_{0} \\
(\mathrm{kA} / \mathrm{m})\end{array}$ & $(\mathrm{T})$ & $\alpha$ \\
\hline $\mathrm{Co}_{40} \mathrm{Fe}_{40-\mathrm{x}} \mathrm{Cr}_{\mathrm{x}} \mathrm{B}_{20}$ & $0 \%$ & 1110 & 1029 & 0.0766 & 0.020 \\
& $3.7 \%$ & 910 & 825 & 0.0862 & 0.025 \\
& $8.8 \%$ & 744 & 760 & 0.1044 & 0.028 \\
& $18 \%$ & 310 & 266 & 0.1775 & 0.023 \\
& & & 420 & 0.2246 & 0.023 \\
$\mathrm{Co}_{40} \mathrm{Fe}_{40-\mathrm{x}} \mathrm{Ni}_{\mathrm{x}} \mathrm{B}_{20}$ & $0 \%$ & 1110 & 1029 & 0.0766 & 0.020 \\
& $12.8 \%$ & 978 & 900 & 0.0846 & 0.012 \\
& $21.6 \%$ & 924 & 820 & 0.0976 & 0.012 \\
$\mathrm{Co}_{40} \mathrm{Ni}_{40-\mathrm{x}} \mathrm{Cr}_{\mathrm{x}} \mathrm{B}_{20}$ & $0 \%$ & 416 & 468 & 0.1557 & 0.070 \\
& $4.8 \%$ & 329 & 390 & 0.1783 & 0.030 \\
& $9 \%$ & 165 & 365 & 0.1818 & 0.035 \\
& $13.2 \%$ & 63 & 361 & 0.1837 & 0.050 \\
\hline \hline
\end{tabular}

contribute to the line-broadening. The deduced magnetic parameters are summarized in Table I. One can see that the linewidth, the magnetization, and the effective damping parameter tend to decrease monotonically as the chromium concentration increases.

Strong angular dependence of magnetic damping (linewidth of FMR spectra) is an indication of structural anisotropy; otherwise the intrinsic Gilbert type damping would be isotropic. A narrower line-width can be taken as an indicator of sample homogeneity and quality.

\section{Magnetoresistance and spin torque switching}

The effect of $\mathrm{Cr}$ content on the tunnel magnetoresistance (TMR) ratio in nano-MTJs with a $2.5 \mathrm{~nm} \mathrm{Co}_{40} \mathrm{Fe}_{40-\mathrm{x}} \mathrm{Cr}_{\mathrm{x}} \mathrm{B}_{20}$ free layer is shown in Fig. 4. A monotonic decrease in TMR ratio is observed for both annealing temperatures. The TMR ratio starts at $\sim 150 \%$ for $\mathrm{x}=0$ and reduces to $\sim 100 \%$ for $\mathrm{x}=7.3 \%$, but there was considerable variation of TMR within a batch of nano-MTJs with the same concentration $\mathrm{x}$ of the free layer. This variation reflects the low yield lift-off

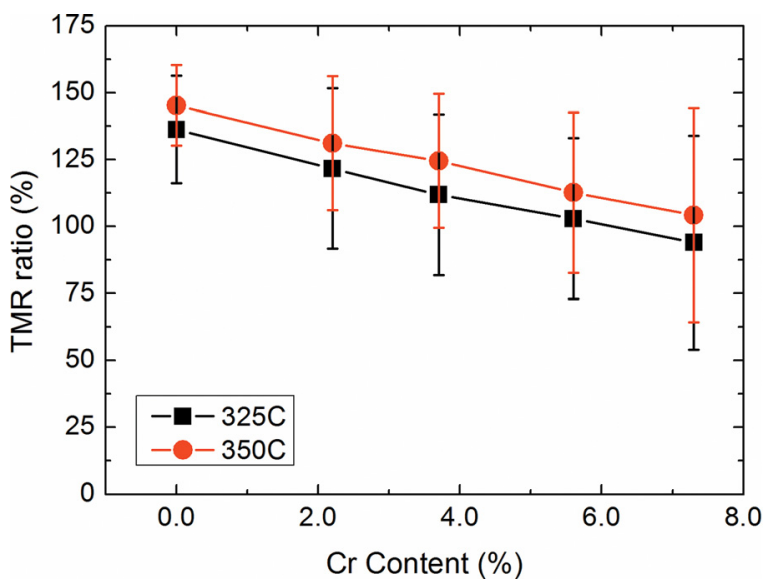

FIG. 4. The effect of $\mathrm{Cr}$ content on the TMR ratio of MTJs with a $\mathrm{Co}_{40} \mathrm{Fe}_{40-\mathrm{x}} \mathrm{Cr}_{\mathrm{x}} \mathrm{B}_{20}$ free layer at these annealing temperatures. process that we employ in our nano-MTJ patterning flow. The non-homogenous $\mathrm{Cr}$ concentration in the free layer can also contribute to the TMR variation of the devices for high concentrations. The resistance $\times$ area product of the MTJs was $\sim 40 \Omega \mu \mathrm{m}^{2}$.

Typical magnetoresistance curves of a nano-MTJ with $\mathrm{Co}_{40} \mathrm{Fe}_{40-\mathrm{x}} \mathrm{Cr}_{\mathrm{x}} \mathrm{B}_{20}$ free layer for $\mathrm{x}=7.3$ is shown in Fig. 5(a). The TMR ratio of this particular device was $\sim 60 \%$ after annealing at $350{ }^{\circ} \mathrm{C}$ for $30 \mathrm{~min}$. The free layer loop is shifted by $8.2 \mathrm{mT}$ due to dipolar coupling, and a compensatory field is applied for the measurement of the pulsed $R-j$ loop of the same device illustrated in Fig. 5(b). Two distinct changes in resistance are observed at $+4.6 \times 10^{5} \mathrm{~A} / \mathrm{cm}^{2}\left(j_{C}^{A P-P}\right)$ and $-5.1 \times 10^{5} \mathrm{~A} / \mathrm{cm}^{2}\left(j_{C}^{P-A P}\right)$. $j_{\text {c(av) }}$ is $4.9 \times 10^{5} \mathrm{~A} / \mathrm{cm}^{2}$. In these measurements, positive current corresponds to electrons tunnelling from pinned layer to free layer. Positive current stabilizes the parallel state in this configuration.

As the $\mathrm{Cr}$ concentration is increased, the critical current density is progressively reduced as shown in Fig. 6 for devices annealed at $325^{\circ} \mathrm{C}$ for $30 \mathrm{~min}$. For $\mathrm{x}=0, j_{c}$ is around $2 \times 10^{6} \mathrm{~A} / \mathrm{cm}^{2}$ and it falls linearly with increasing $\mathrm{Cr}$ content. The lowest value of $j_{c}, 4.9 \times 10^{5} \mathrm{~A} / \mathrm{cm}^{2}$ is found when $\mathrm{x}=7.3$.

\section{DISCUSSION}

The magnetic moment per formula unit for amorphous $3 d$ alloys may be estimated from the magnetic valence model. $^{21}$ The basic assumption of the model is strong
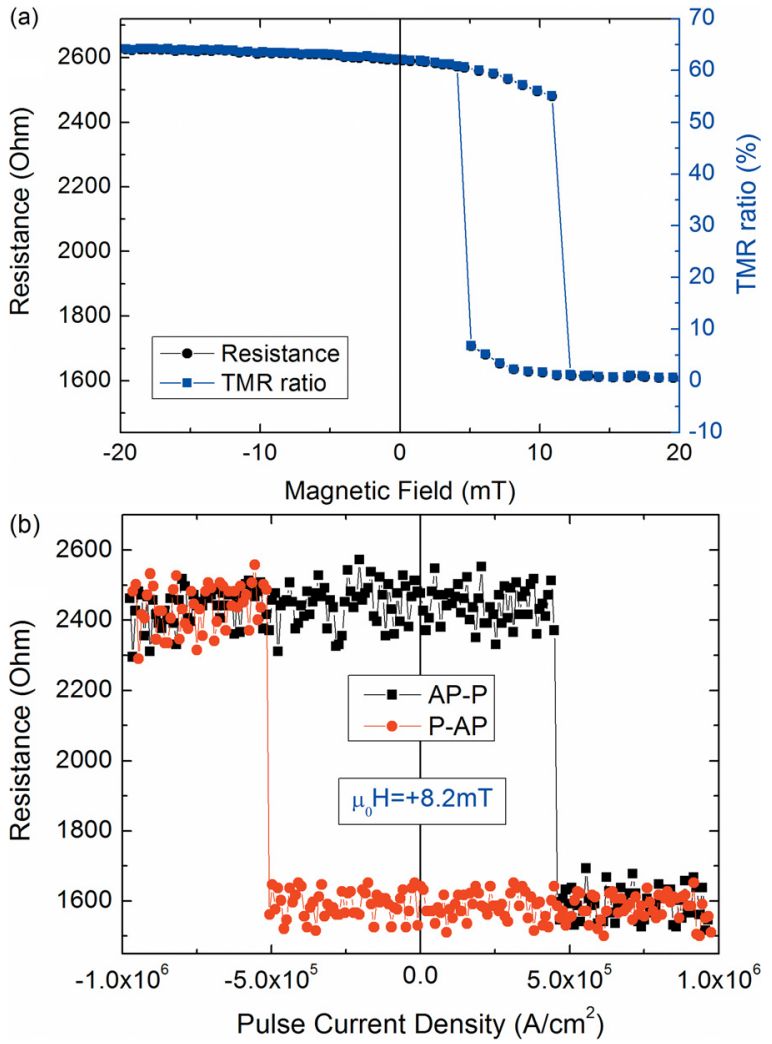

FIG. 5. (a) Resistance and TMR ratio curves and (b) $R-j$ loop of a nano-MTJ with a $\mathrm{Co}_{40} \mathrm{Fe}_{32.7} \mathrm{Cr}_{7.3} \mathrm{~B}_{20}$ free layer. Pulse width was $1 \mathrm{~ms}$ during the measurement. Nanopillar size is $90 \times 170 \mathrm{~nm}^{2}$. 


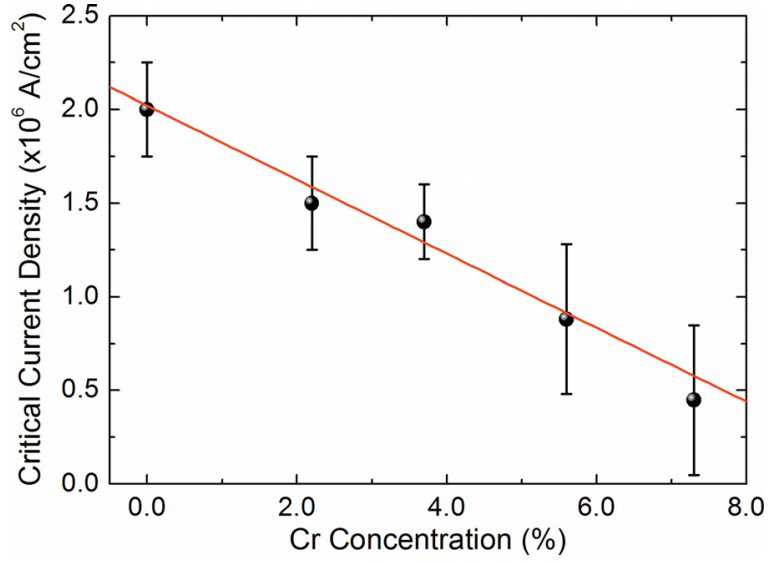

FIG. 6. The effect of $\mathrm{Cr}$ content on the $j_{c}$ for the nano-MTJs with $\mathrm{Co}_{40} \mathrm{Fe}_{40-\mathrm{x}} \mathrm{Cr}_{\mathrm{x}} \mathrm{B}_{20}$ free layer. Red line is a linear fit to the data.

ferromagnetism, in other words the majority spin $d$-band is full. The average magnetic moment per atom is then

$$
\langle\mu\rangle=\left(\left\langle\mathrm{Z}_{\mathrm{m}}\right\rangle+2 N_{s}^{\uparrow}\right) \mu_{B},
$$

where $\mathrm{Z}_{\mathrm{m}}$ is the magnetic valence of the atom ( 2 for Fe, 1 for $\mathrm{Co}, 0$ for $\mathrm{Ni},-6$ for $\mathrm{Cr}$, and -3 for $\mathrm{B}$ ) and $N_{\mathrm{s}}$ the number of electrons in the $s$ conduction band. The magnetic valence is defined as $\mathrm{Z}_{\mathrm{m}}=2 N_{d}^{\uparrow} \mathrm{Z}$, where $N_{d}^{\uparrow}$ is taken as either 5 for 0 , and $\mathrm{Z}$ is the valence of the atom ( 8 for Fe, 9 for Co, 10 for $\mathrm{Ni}, 6$ for $\mathrm{Cr}$, and 3 for B). Taking $N_{s}^{\uparrow}=0.3$, we calculate $\langle\mu\rangle$ for the end members as follows:

$$
\mathrm{Co}_{40} \mathrm{Fe}_{40} \mathrm{~B}_{20}-1.20 \mu_{B}, \quad \mathrm{Co}_{40} \mathrm{Ni}_{40} \mathrm{~B}_{20}-0.40 \mu_{B} .
$$

The values of the magnetisation of the as-deposited films deduced from the SQUID measurements and from FMR at room temperature are in reasonable agreement. For these two end members the values are $1.25 \mu_{\mathrm{B}}$ and $0.57 \mu_{\mathrm{B}}$ (SQUID) and $1.16 \mu_{\mathrm{B}}$ and $0.61 \mu_{\mathrm{B}}$ (FMR). Agreement between these two independent measurements of magnetisation with the zero temperature prediction of the model is satisfactory.

The predicted variation of the magnetic moment with $\mathrm{x}$ in the three systems is shown by the red lines in Figure 2. Here, we can see that the trend is reproduced, but the moment falls less rapidly than predicted in all three systems. This may reflect a shortcoming of the magnetic valence model. It takes no account of the local environment of the atoms. This has some influence as shown by the slight increase in magnetisation on thermal annealing. The annealing does not alter the elemental composition of the alloy-the only consideration is the magnetic valence model-but it does relax the local environments while maintaining an amorphous state. The distribution of $\mathrm{Cr}$ and the other $3 d$ atoms around the $\mathrm{Fe}, \mathrm{Co}$, or $\mathrm{Ni}$ sites will influence the moment and its average values, as in the Jaccarino-Walker model. ${ }^{22}$

The decrease in moment with $\mathrm{Cr}$ substitution is better reproduced if we take $\mathrm{Z}_{\mathrm{m}}$ for $\mathrm{Cr}$ as -5 instead of -6 . This indicates that the assumption $N_{3 d}^{\uparrow}=0$ for $\mathrm{Cr}$ is too drastic and that is so better modelled for these alloys with 0.5 electrons in the spin $\uparrow d$-band.
The benefit of reducing magnetisation of the free layer in spin torque switching is evident (Fig. 6). A similar effect has been observed by Kubota et al. on $\left(\mathrm{Co}_{75} \mathrm{Fe}_{25}\right)_{80-\mathrm{x}}$ $\mathrm{Cr}_{\mathrm{x}} \mathrm{B}_{20} \cdot{ }^{18}$ They replaced $(\mathrm{CoFe})$ in $\mathrm{CoFeB}$ with $\mathrm{Cr}$ and reported a decrease of $j_{c 0}$ by a factor of 2 for $10 \% \mathrm{Cr}$. We observed a reduction in $j_{c}$ by a factor of four for $7.3 \% \mathrm{Cr}$, mainly due to the decrease in the $M_{s}$ of $\mathrm{Co}_{40} \mathrm{Fe}_{40-\mathrm{x}} \mathrm{Cr}_{\mathrm{x}} \mathrm{B}_{20}$ free layer. It is important to note that the coercivity of the device is also decreased with increasing $\mathrm{Cr}$ content. Therefore, it is not possible to use material with higher $\mathrm{Cr}$ concentration $(>10 \%)$ for spin transfer torque devices due to the lack of a bi-stable state.

The Gilbert damping is essentially unchanged by $\mathrm{Cr}$ substitution and the TMR holds up well (Fig. 4). The reduction in TMR ratio may be due to a reduction in tunnelling spin polarization in MTJs with Cr substitution.

\section{CONCLUSIONS}

Chromium, and to a lesser extend nickel, substitution for iron is effective at reducing the magnetisation of $\mathrm{Co}_{40} \mathrm{Fe}_{40} \mathrm{~B}_{20}$ with little influence on the Gilbert damping parameter $\alpha$. The moment and its reduction can be explained semi-quantitatively in terms of the magnetic valence model, especially if the magnetic valence of $\mathrm{Cr}$ is taken as -5 .

The $\mathrm{Co}_{40} \mathrm{Fe}_{40-\mathrm{x}} \mathrm{Cr}_{\mathrm{x}} \mathrm{B}_{20}$ system is the best of the three we have considered for improving the performance of $\mathrm{MgO}$ based magnetic tunnel junctions. The decrease in tunnel magnetoresistance with $\mathrm{Cr}$ substitution is more than offset by the reduction in current density $j_{c}$ required for spin torque switching of the free layer. The current density is reduced by a factor of four to $0.49 \times 10^{6} \mathrm{~A} / \mathrm{cm}^{2}$ when $\mathrm{x} \approx 7.3$. The $\mathrm{Co}_{40} \mathrm{Fe}_{33} \mathrm{Cr}_{7} \mathrm{~B}_{20}$ films may be useful for the free layers in memory cells and other spin transfer torque devices.

\section{ACKNOWLEDGMENTS}

The authors would like to thank Dr. G. Feng for $\mathrm{Co}_{40} \mathrm{Fe}_{40-\mathrm{x}} \mathrm{Ni}_{\mathrm{x}} \mathrm{B}_{20}$ samples and Dr. M. Venkatesan and Dr. P. Stamenov for magnetic measurements. Authors also would like to thank Professor B. Aktas for fruitful discussions on ferromagnetic resonance results. This work was supported by Science Foundation Ireland under the MANSE contract 05/IN/1850. It was also conducted under the framework of the INSPIRE programme, funded by the Irish Government's Programme for Research in Third Level Institutions, Cycle 4, National Development Plan 2007-2013.

${ }^{1}$ J. C. Slonczewski, J. Magn. Magn. Mater. 159(1-2), L1-L7 (1996).

${ }^{2}$ L. Berger, Phys. Rev. B 54(13), 9353 (1996).

${ }^{3}$ H. Kubota, A. Fukushima, Y. Ootani, S. Yuasa, K. Ando, H. Maehara, K. Tsunekawa, D. D. Djayaprawira, N. Watanabe, and Y. Suzuki, IEEE Trans. Magn. 41(10), 2633-2635 (2005).

${ }^{4}$ M. Tsoi, A. G. M. Jansen, J. Bass, W. C. Chiang, M. Seck, V. Tsoi, and P. Wyder, Phys. Rev. Lett. 80(19), 4281 (1998).

${ }^{5}$ J. A. Katine, F. J. Albert, R. A. Buhrman, E. B. Myers, and D. C. Ralph, Phys. Rev. Lett. 84(14), 3149 (2000).

${ }^{6}$ Y. Huai, F. Albert, P. Nguyen, M. Pakala, and T. Valet, Appl. Phys. Lett. 84(16), 3118-3120 (2004).

${ }^{7}$ Z. Diao, D. Apalkov, M. Pakala, Y. Ding, A. Panchula, and Y. Huai, Appl. Phys. Lett. 87(23), 232502-232503 (2005).

${ }^{8}$ Z. Li and S. Zhang, Phys. Rev. B 68(2), 024404 (2003). 
${ }^{9}$ J. Z. Sun, Phys. Rev. B 62(1), 570 (2000).

${ }^{10}$ J. A. Katine and E. E. Fullerton, J. Magn. Magn. Mater. 320(7), 1217-1226 (2008).

${ }^{11}$ K. Moorjani and J. M. D. Coey, Magnetic Glasses (Elsevier, 1984).

${ }^{12}$ S. Ikeda, J. Hayakawa, Y. Ashizawa, Y. M. Lee, K. Miura, H. Hasegawa, M. Tsunoda, F. Matsukura, and H. Ohno, Appl. Phys. Lett. 93(8), 082508 (2008).

${ }^{13}$ D. D. Djayaprawira, K. Tsunekawa, M. Nagai, H. Maehara, S. Yamagata, N. Watanabe, S. Yuasa, Y. Suzuki, and K. Ando, Appl. Phys. Lett. 86(9), 092502 (2005).

${ }^{14}$ J. Hayakawa, S. Ikeda, F. Matsukura, H. Takahashi, and H. Ohno, Jpn. J. Appl. Phys., Part 2: Lett. 44(16-19), L587-L589 (2005).

${ }^{15}$ S. Ikeda, J. Hayakawa, Y. M. Lee, T. Tanikawa, F. Matsukura, and H. Ohno, J. Appl. Phys. 99(8), 08A907-903 (2006).
${ }^{16}$ Y. M. Lee, J. Hayakawa, S. Ikeda, F. Matsukura, and H. Ohno, Appl. Phys. Lett. 89(4), 042506 (2006).

${ }^{17}$ K. Oguz, Ph.D. dissertation, Trinity College Dublin, 2010.

${ }^{18}$ H. Kubota, A. Fukushima, K. Yakushiji, S. Yakata, S. Yuasa, K. Ando, M. Ogane, Y. Ando, and T. Miyazaki, J. Appl. Phys. 105(7), 07D117 (2009).

${ }^{19}$ R. Topkaya, M. Erkovan, A. Ozturk, O. Ozturk, B. Akta, and M. Ozdemir, J. Appl. Phys. 108(2), 023910-023919 (2010).

${ }^{20}$ G. D. Fuchs, J. C. Sankey, V. S. Pribiag, L. Qian, P. M. Braganca, A. G. F. Garcia, E. M. Ryan, Z.-P. Li, O. Ozatay, D. C. Ralph, and R. A. Buhrman, Appl. Phys. Lett. 91(6), 062507-062503 (2007).

${ }^{21}$ A. Williams, V. Moruzzi, A. Malozemoff, and K. Terakura, IEEE Trans. Magn. 19(5), 1983-1988 (1983).

${ }^{22}$ V. Jaccarino and L. R. Walker, Phys. Rev. Lett. 15(6), 258-259 (1965). 